\title{
Macro- and Microphysical Characteristics of Precipitating and Non-Precipitating Stratocumulus Clouds over Eastern China
}

\author{
Sicong Li, Yunying Li *, Guorong Sun and Zhixian Lu \\ Institute of Meteorology and Oceanography, National University of Defense Technology, Nanjing 211101, China; \\ atmos_lsc@outlook.com (S.L.); sungr09@lzu.edu.cn (G.S.); luzhixian701@163.com (Z.L.) \\ * Correspondence: ghlyy@mail.iap.ac.cn
}

Received: 29 March 2018; Accepted: 19 June 2018; Published: 21 June 2018

\begin{abstract}
Stratocumulus (Sc) is the most common cloud type in China. Sc clouds may or may not be accompanied by various types of precipitation that are representative of different macroand microphysical characteristics. The finely resolved CloudSat data products are used in this study to quantitatively investigate the macro- and microphysical characteristics of precipitating and non-precipitating Sc (PS and NPS, respectively) clouds over Eastern China (EC). Based on statistical information extracted from the CloudSat data, Sc clouds are highly likely to occur alone, in association with liquid precipitation, or in association with drizzle over $25 \%$ of EC. The cloud bases of NPS clouds are higher than those of PS clouds, although the latter display higher cloud top heights and thicker cloud thicknesses. The spatial distributions of microphysical characteristics differ between PS and NPS clouds. The magnitudes of microphysical characteristics in NPS clouds are relatively small, whereas the magnitudes of microphysical characteristics in PS clouds are relatively large and peak in response to certain circulation patterns and over certain terrain. In NPS clouds, condensation is the primary mechanism for hydrometeor particle growth, and the liquid water content and effective radius increase with height. Once the particles are too large to be supported by the updrafts, cloud droplets form raindrops. In PS clouds, raindrops increase continuously in size via collision-coalescence processes as they fall, leading to an increase in the liquid water content and effective radius from cloud top to cloud base. The CFRHDs (contoured frequency by relative height diagrams) of radar reflectivity in different cloud thickness indicate the cloud evolution and the precipitation formation process. In thinner clouds, downward particle growth by coalescence and upward particle growth by condensation occur in the upper and lower layers of clouds, respectively. With the increases in cloud thickness, the collision-coalescence process becomes apparent in all cloud layers, and the upward condensation process is less pronounced near the cloud base. Particles can grow for a long period of time and increase to larger sizes in thicker clouds, resulting in increased precipitation frequency. In clouds thicker than $1.92 \mathrm{~km}$, the continuous transition from cloud to drizzle to rain by the collision-coalescence process takes place mostly in the upper layers.
\end{abstract}

Keywords: stratocumulus; cloud physical characteristics; Eastern China

\section{Introduction}

Stratocumulus (Sc) is the most widely occurring cloud type in the atmosphere. Sc clouds cover $23 \%$ of the ocean area and $12 \%$ of the land area over the globe; thus, they cover a much greater total area than other cloud types [1]. Klein and Hartmann [2] pointed out that Sc clouds occur mainly in four world regions, and China is one of these regions.

In China and the surrounding areas, Sc clouds appear mainly in three regions. These regions are the southern slope of the Tibetan Plateau; the seas between southern Japan and the Philippines; 
and continental Eastern China (EC), which lies on the lee side of the Tibetan Plateau (Figure 1). According to $\mathrm{Yu}$ et al. [3], the westerlies in the lower troposphere flow around the plateau to the north and south, converge over EC on the lee side of the Tibetan Plateau, and form a rising airflow. The cloud top height is limited by the inversion layer and the divergence layer in the middle troposphere, leading to the production of Sc but not other cloud types [4]. The present study focuses solely on Sc clouds over Eastern China $\left(20-45^{\circ} \mathrm{N}, 105-130^{\circ} \mathrm{E}\right)$ and its surrounding seas. This area is marked by a yellow rectangle in Figure 1.

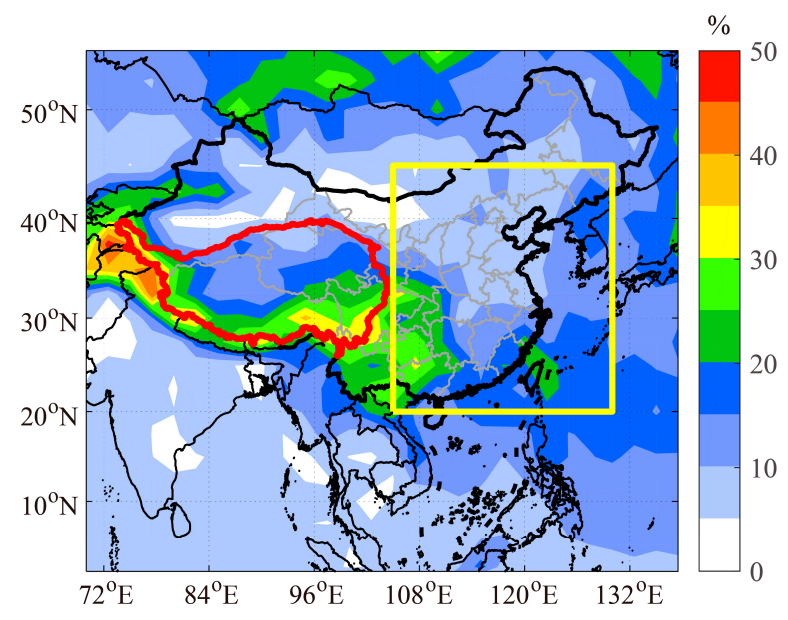

Figure 1. Spatial distribution of the frequency of occurrence of Sc clouds detected by CloudSat from June 2006 to December 2010. The yellow rectangular box indicates the area of interest in this study, and the thick red contour denotes the edge of the Tibetan Plateau.

Sc clouds may or may not be accompanied by precipitation, which represents different macro- and microphysical characteristics [5,6] and different cloud radiative forcings [7]. In situ observations gathered via field experiments indicate that drizzle is commonly associated with Sc clouds [8]. The formation mechanisms of liquid precipitation and solid precipitation differ significantly; only the liquid precipitating Sc clouds are discussed in this work.

Previous studies have investigated the macro- and microphysical characteristics of Sc clouds on the basis of the observations or global climate models. Leon et al. [9] found that the Sc cloud drizzle frequency is higher and drizzle intensity is stronger in the midlatitude Sc regions. Nakajima et al. [10] demonstrated that the droplet growth process from small cloud drops to drizzle to rain via drizzle proceeds monotonically based on data from CloudSat and MODIS. They also found that the growth of drops by coalescence becomes very efficient when the drop effective radius exceeds a critical radius (about $14 \mu \mathrm{m}$ ), where warm rain starts developing quickly [11]. The process of drizzle initiation in shallow Sc clouds can be delayed by the turbulent mixing, but turbulent mixing is essential for drizzle further development [12]. Wood [13] reviews the current knowledge of the climatological, structural, and organizational aspects of Sc clouds and noted that more and better observations of Sc clouds are required in midlatitude regions. However, as the unique continental Sc cloud region, there are few studies available that report the macro- and microphysical characteristics of Sc clouds over EC. Global Sc clouds are primarily found in June, July and August, while the occurrence frequency of Sc over EC peaks in January and December, but drops to its minimum in July [14]. The frequent Sc cover in cold seasons reflects shortwave radiation, leading to large negative net cloud radiative forcing [2] and the lowest temperature in the EC continent compared to other regions of similar latitude [15]. In most of the current state-of-the-art general climate models, the Sc cloud radiation effect is recognized to cause larger biases than other cloud types [16] and there is a large uncertainty and a common underestimation of the shortwave cloud radiative forcing in EC [17]. In climate models, the parameterization of cloud properties is critical for the prediction of the cloud response to climate change [18]. But whether the 
cloud macroscopic characteristics and microphysical process and properties can be properly described in models remains an open question. For instance, the number concentration of different hydrometeor species in some one-moment microphysics schemes are diagnosed, not predicted; it is set as a constant for a given precipitation species $[19,20]$, which is inconsistent with reality.

CloudSat is the only satellite that can provide the detailed vertical structure of clouds from space. The CloudSat data products have been employed in some studies. Rajeevan et al. [21] used four years of CloudSat data to document the mean vertical structure of clouds associated with the Indian summer monsoon and its intra-seasonal variability. Jiang et al. [22] found that a marked vertical tilting structure in cloud water was illustrated during the northward propagation of the boreal summer intra-seasonal variability from the equatorial zone to the Indian Continent based on CloudSat observation. Zhang et al. [23] used four CloudSat products to investigate the daytime-nighttime difference in the macro- and microphysical characteristics of single-layer stratus clouds over Eastern China during the boreal cold season. Kiran et al. [24] examined the role of the vertical structure of cloud microphysical properties in cloud radiative forcing parameters at the top-of-the atmosphere on basis of the CloudSat and CERES.

Based on the CloudSat dataset, the statistical frequency of occurrence of precipitating Sc (PS) clouds (includes liquid precipitation and drizzle) and non-precipitating Sc (NPS) clouds in EC are approximately $25 \%$ and $70 \%$, respectively, and these types of clouds differ significantly in terms of their macro- and microphysical characteristics. This study uses CloudSat data products to investigate the macro- and microphysical characteristics of both PS and NPS clouds over EC. We hope that the quantitative results presented here will contribute to a better and more comprehensive understanding of the precipitation mechanisms that operate in Sc clouds, in addition to providing the satellite retrievals needed to validate the representations of cloud microphysical processes in the relevant numerical models. Section 2 provides a brief introduction to the data used in this study. Sections 3 and 4 contain the statistical results of the macroscopic characteristics and the microphysical properties of PS and NPS clouds. Section 5 provides a brief summary and concludes the paper.

\section{Data}

This study employs cloud macro- and microphysical properties derived from CloudSat data products (http: / / www.cloudsat.cira.colostate.edu/) that cover the period from June 2006 to December 2010. The clouds detected by CloudSat are classified into eight types, specifically, stratus (St), stratocumulus (Sc), cumulus ( $\mathrm{Cu}$ ), altocumulus (Ac), altostratus (As), nimbostratus (Ns), and deep convective (DC) clouds and high clouds. Sc clouds are defined as inhomogeneous clouds with base heights less than $2.0 \mathrm{~km}$ above ground level, horizontal scales of $10^{3} \mathrm{~km}$, shallow vertical extents, and liquid water paths greater than zero; they either are or are not accompanied by drizzle or snow $[25,26]$.

The Cloud Profiling Radar (CPR) onboard CloudSat operates at $94 \mathrm{GHz}$. It is able to penetrate optically thick clouds to detect multi-layer cloud systems, but it cannot detect thin cirrus clouds with small ice water contents $[25,27]$. The Cloud-Aerosol LIDAR and Infrared Pathfinder Satellite Observation (CALIPSO) LIDAR (CALIOP) is sensitive enough to detect the optically thin cirrus clouds that are missed by radar. Combining LIDAR and radar measurements can provide effective cloud detection and characterization due to their unique complementary capabilities [28]. In this study, we primarily employ the combined LIDAR and radar product 2B-CLDCLASS-LIDAR and the CPR product 2B-CLDCLASS whenever LIDAR data are unavailable. Both of these cloud products provide information for up to 10 cloud layers, including cloud types, cloud bases, top heights, and especially precipitation types (e.g., drizzle, liquid precipitation, solid precipitation, or no precipitation).

The precipitation occurrence flag and its phase are identified by combining the maximum reflectivity in lower radar gate and the attenuation of cloud and precipitation. Considering that the closest four bins above the surface are contaminated by surface clutter, the radar reflectivity of the fifth bin $\left(Z_{5 t h}\right)$ above the surface is used as a proxy for the surface echo. Precipitation occurrence is 
identified if the fifth bin's radar reflectivity $\left(Z_{5 t h}\right)$ greater (or equal) than the threshold. The threshold is determined by the fifth bin's temperature as reported by an ECMWF model. Then, if the bright band is identified in the radar signal or the surface temperature is warmer than $2{ }^{\circ} \mathrm{C}$, the precipitation is liquid; otherwise it is solid. Additionally, $-18 \mathrm{dBZ}$ is selected to detect possible drizzle for the boundary layer clouds. This algorithm is described by Sassen and Wang [29] and Hudak et al. [30]. In this study, the CloudSat cloud layer precipitation flag is used directly to categorize the Sc clouds into PS and NPS clouds. As mentioned above, PS clouds only include Sc clouds that produce both liquid precipitation and drizzle; solid precipitation is excluded.

The CloudSat data product 2B-GEOPROF uses the data from the CPR to determine whether the levels in the vertical direction contain significant radar echoes from hydrometeors and includes an estimate of the radar reflectivity factor for each bin. The "bin" is the basic unit of storage in CloudSat. The resolution of each bin is approximately $1.7 \mathrm{~km}$ along-track by $1.3 \mathrm{~km}$ across-track and $240 \mathrm{~m}$ in the vertical direction. The CPR cloud mask included with 2B-GEOPROF provides a confidence check on the CPR output. High values of the cloud mask represent cloud detections with lower chances of false detection; mask values greater than 30 indicate that clouds are reliably detected with an uncertainty less than $2 \%$ [31]. In addition, we also observe a noticeable uncertainty in the bins near the surface due to the CPR surface return contaminates. Consequently, bin samples below $0.5 \mathrm{~km}$ and cloud mask values less than 30 are discarded in this study.

The CloudSat data product 2B-CWC-RVOD provides cloud microphysical properties, including liquid/ice water contents, liquid/ice effective radii, liquid/ice number concentrations, liquid/ice distribution width parameters, and the uncertainties in the values of all of these properties in each range bin. The uncertainties of PS and NPS clouds microphysics are shown in Table 1. The product 2B-CWC-RVOD uses the radar reflectivity together with visible optical depth to constrain the cloud retrievals more tightly than in the radar only product (2B-CWC-RO), presumably yielding more accurate results [32]. However, some factors may affect the retrieval of the cloud liquid water content and other microphysical properties. One factor is the supercooled liquid or mixed phase clouds. The Forward Model of the CloudSat retrieval algorithm assumes that the bin colder than $-20{ }^{\circ} \mathrm{C}$ and warmer than $0{ }^{\circ} \mathrm{C}$ is pure ice and pure liquid; otherwise, the ice and liquid solutions are scaled linearly with temperature to obtain a profile that smoothly transitions from all ice to all liquid. The composite profile does not accurately capture the mixed phased cloud structure [33]. Another factor is the algorithm assumes a lognormal size distribution of liquid cloud droplets [34]. The liquid cloud droplet distribution may depart from the lognormal distribution especially in precipitating and drizzling clouds. In addition, the large raindrops in precipitation increase the radar reflectivity, and the radar reflectivity may exceed the range allowed by the algorithm. Thus, the retrieved liquid water content is usually nonconvergent in heavy precipitation clouds [35]. Despite the retrieved liquid water content being insufficient in certain situations, some previous studies have shown consistent results in representing the clouds climate features from the 2B-CWC-RVOD [21-24].

Table 1. The mean fractional uncertainties in the 2B-CWC-RVOD retrieved PS and NPS clouds microphysical properties including the liquid water content, liquid number concentration and liquid effective radius. The uncertainties are expressed in percent and are rounded to the nearest integer.

\begin{tabular}{cccc}
\hline & $\begin{array}{c}\text { Liquid } \\
\text { Water Content }\end{array}$ & $\begin{array}{c}\text { Liquid Number } \\
\text { Concentration }\end{array}$ & $\begin{array}{c}\text { Liquid } \\
\text { Effective Radius }\end{array}$ \\
\hline Non-precipitating Sc clouds & $26 \%$ & $31 \%$ & $6 \%$ \\
Precipitating Sc clouds & $25 \%$ & $28 \%$ & $5 \%$ \\
\hline
\end{tabular}

We gather the different macro- and microphysical properties of clouds supplied by the different CloudSat data products in each range bin, as well as the macroscopic features in the 10 cloud layers. For convenience, we establish a data set in which the cloud microphysical properties are matched with each corresponding cloud layer. The data set contains more than 10 parameters describing cloud 
macro- and micro-properties along the CloudSat orbit. We investigate the macro- and microphysical characteristics of PS and NPS clouds over EC using this data set. There are 1,133,712 profiles that pass through the selected region and contain Sc clouds and 1,532,235 and 2,307,487 bin samples of PS and NPS clouds, respectively. Here, we focus only on the warm rain process in Sc clouds due to the limited sample number of ice particles.

\section{Stratocumulus Macroscopic Characteristics}

Cloud macroscopic characteristics, such as the number of cloud layers, cloud top and base heights, and cloud thicknesses, are key factors that affect radiation budgets, the hydrological cycle, and precipitation formation mechanisms in clouds [36]. Warren et al. [37] pointed out that it is common for Sc clouds to occur simultaneously with other cloud types at different levels in the atmosphere over the same location; the effects of Sc clouds on radiation budgets depend on whether other clouds are present. However, the CloudSat data indicate that Sc clouds are much more likely to occur alone $(70.31 \%)$ than to be accompanied by other cloud types over EC. When Sc clouds occur with other cloud types, they are typically medium or high cloud types, such as high cloud, altostratus (As), and altocumulus (Ac) (Figure 2a). The average separation distance between the upper cloud level and Sc is $3.08 \mathrm{~km}$. This distance may be due to the mutual exclusion tendency of different low cloud types.

Whether Sc clouds generate precipitation is strongly influenced by the generating circulation pattern, water vapor conditions, and the terrain. Figure $2 b$ shows the spatial distribution of the frequency of precipitation from Sc clouds over EC. Considering the variations in cloudiness at different spatial and temporal scales, the precipitation frequency can be distributed over a $2.5^{\circ} \times 2.5^{\circ}$ grid [38]. The frequency of precipitation from Sc clouds displays a clear north/south boundary at $35^{\circ} \mathrm{N}$; the precipitation frequency is relatively large to the south, where it exceeds $25 \%$. Because the soil humidity is high and evaporation is strong in the south of China, and the westerlies' southern branches transport warm and wet air from the Bay of Bengal to southern China and converge with the northern branches on the lee side of the plateau; most Sc clouds over southern China generate precipitation, particularly the Sichuan Basin. At the same latitude, the frequency of precipitation from Sc clouds is larger over the ocean $(>30 \%)$ than that over land areas $(<30 \%)$ due to the abundance of water vapor over the ocean. There is a large center of precipitation frequency located over the northeastern part of Taiwan; Sc clouds are more likely to occur over this area in cold seasons, and the combined effects of northeasterly Asian monsoons and landforms lead to this elevated precipitation frequency.
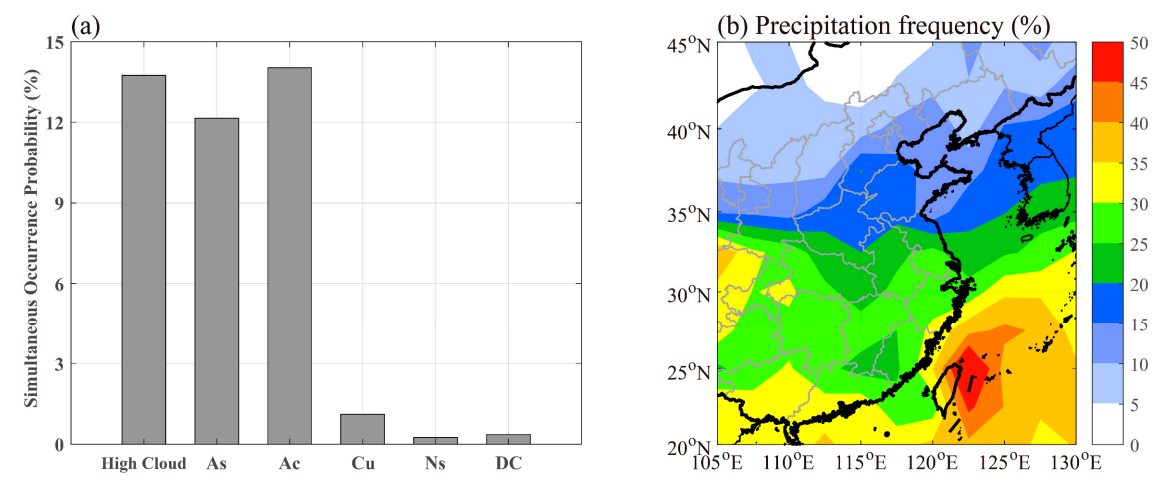

Figure 2. (a) Conditional occurrence probabilities of Sc clouds accompanied by six other cloud types, High cloud, altostratus (As), altocumulus (Ac), cumulus ( $\mathrm{Cu}$ ), nimbostratus (Ns) and deep convective (DC) clouds; Sc clouds occur alone in 73\% of the observed cases; (b) Spatial distribution of precipitation frequency of Sc clouds detected by CloudSat over EC.

Figure 3 shows the spatial distribution of the average cloud base and top heights and thicknesses of PS and NPS clouds over EC. Given the homogeneous surface properties, the cloud bases, top heights, 
and thicknesses of both PS and NPS clouds are much more uniform over the ocean than over land areas. When Sc clouds occur over the ocean, most of the cloud base heights of NPS clouds are less than $1.0 \mathrm{~km}$, the cloud top heights are less than $1.75 \mathrm{~km}$, and the cloud thicknesses range from approximately 0.5 to $0.7 \mathrm{~km}$. Over ocean areas, the cloud base heights of PS clouds are generally less than $0.75 \mathrm{~km}$, the cloud top heights exceed $2.25 \mathrm{~km}$, and the cloud thickness is larger than $1.44 \mathrm{~km}$. Compared with eight subtropical and midlatitude ocean Sc regions analyzed by Leon et al. [9], the average cloud top height of Sc over the EC ocean is the highest. For Sc clouds over land areas, the large centers of both PS and NPS cloud bases and top heights are located over the Loess Plateau (33-41 $\left.{ }^{\circ} \mathrm{N}, 100-114^{\circ} \mathrm{E}\right)$ and Inner Mongolian Plateau ( $\left.40-50^{\circ} \mathrm{N}, 106-120^{\circ} \mathrm{E}\right)$; the plateaus' average elevation is about $1000-2000 \mathrm{~m}$. Affected by the terrain height, the base and top heights of Sc clouds increase from the southeast coast to the northwest direction, and Sc cloud bases and top heights over the plateau are more than $1.0 \mathrm{~km}$ higher than that over the southeast coast. The cloud base and top heights of NPS clouds are approximately $0.25 \mathrm{~km}$ higher and $0.5 \mathrm{~km}$ lower than those of PS clouds, respectively, at any given elevation. In summary, the cloud top heights of PS clouds are greater, the cloud base heights are lower, and the cloud thicknesses are greater than those of NPS clouds.
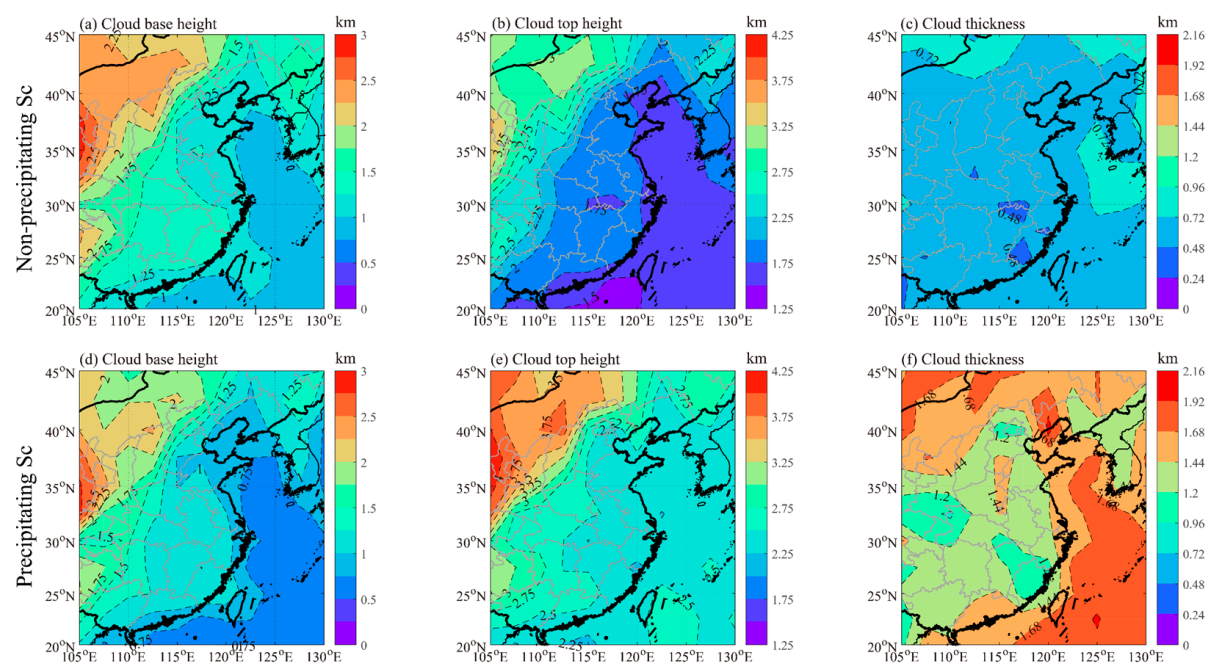

Figure 3. Spatial distributions of average cloud base heights $(\mathbf{a}, \mathbf{d})$, top heights $(\mathbf{b}, \mathbf{e})$ and cloud thicknesses (c,f) of NPS $(\mathbf{a}-\mathbf{c})$ and PS $(\mathbf{d}-\mathbf{f})$ clouds over EC.

As shown in Figure 3f, minima in the thicknesses of PS clouds occur over the Sichuan Basin, the Southeast Hills, and the Korean Peninsula. In these areas, the cloud top height of Sc clouds is lower because it is limited by the atmospheric boundary layer. The cloud base height relative to the ocean surface is also higher because of the higher terrain, which results in thinner Sc clouds. The abundant water vapor over the ocean also causes the average cloud thickness over the ocean to be $0.3 \mathrm{~km}$ greater than that over land areas at the same latitude.

\section{Stratocumulus Microphysical Characteristics}

\subsection{Probability Density Function of Stratocumulus Microphysical Characteristics}

The probability density functions (PDF) of the microphysical characteristics of Sc clouds describe how the probability of occurrence of the values of microphysical characteristics varies across a certain range of values. Figure 4 shows PDFs of the microphysical characteristics of PS and NPS clouds, including their radar reflectivity, liquid water content, liquid effective radius, liquid number concentration, and liquid distribution width parameters, as detected by CloudSat over EC. The PDFs are calculated as the ratio of the bin sample number in each interval (with the ranges of values divided 
into 100 equal intervals) to the total bin sample number, with which most PDFs of microphysical characteristics are normalized.

(a) Radar reflectivity $(\mathrm{dBz})$

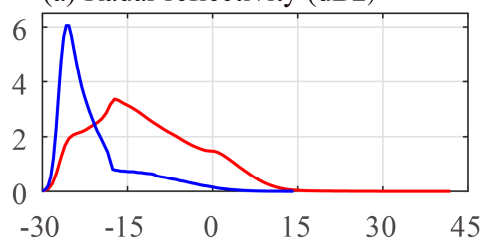

(e) (c) Liquid number concentration $\left(\mathrm{cm}^{-3}\right)$

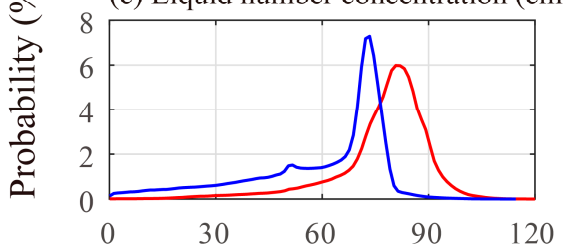

(b) Liquid water content $\left(\mathrm{mg} \cdot \mathrm{m}^{-3}\right)$

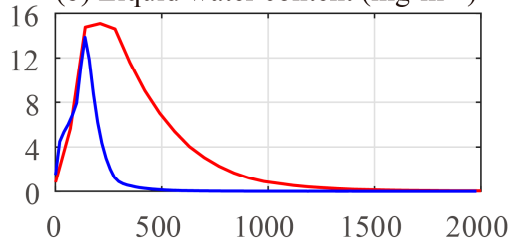

(d) Liquid effective radius $(\mu \mathrm{m})$

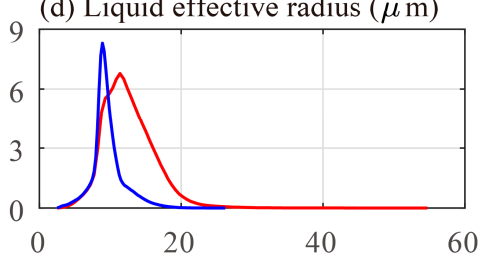

0

60

(e) Liquid distribution width parameter : --
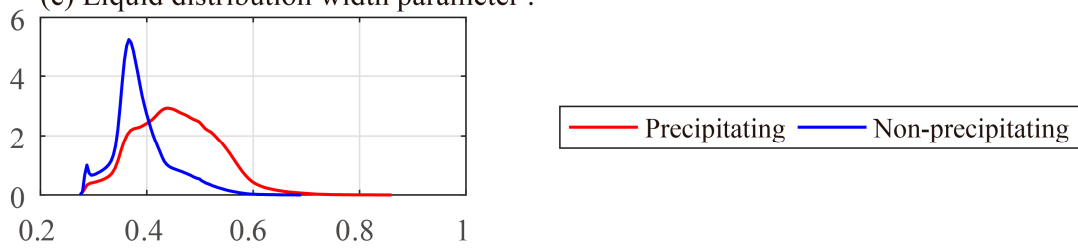

Figure 4. Probability density functions (PDFs) of microphysical characteristics of Sc clouds, including radar reflectivity (a); liquid water content (b); liquid effective radius (c); liquid number concentration (d) and liquid distribution width parameter (e) detected by CloudSat over EC. Red and blue lines represent the PDFs of microphysical characteristics in PS and NPS clouds, respectively.

Both the identification of precipitation and the retrieval of cloud properties are based on radar reflectivity [39]. The radar reflectivity values of Sc clouds range from -30 to $20 \mathrm{dBZ}$ (Figure 4a). In particular, the declared minimum detectable signal of CPR is $-29 \mathrm{dBZ}$; some hydrometeor layers have a backscatter cross section that generates a signal near or below $-29 \mathrm{dBZ}$. The PDFs of radar reflectivity for both PS and NPS clouds have a single-peaked structure. The maximum probabilities for NPS and PS clouds are located around $-26 \mathrm{dBZ}$ and $-17 \mathrm{dBZ}$, respectively; the maximum probability for NPS clouds is significantly greater than that for PS clouds. The PDFs indicate that the reflectivity factors of PS clouds are greater than those of NPS clouds. Suzuki et al. [11,40] noted that, in warm clouds, radar reflectivity values of less than $-20 \mathrm{dBZ}$, from -15 to $0 \mathrm{dBZ}$, and from 0 to $15 \mathrm{dBZ}$ correspond to cloud particles, drizzle, and raindrops, respectively. The PDFs of radar reflectivity presented in this study corroborate this conclusion.

The PDFs of liquid water content are shown in Figure 4b. The liquid water contents in PS clouds are significantly greater than those in NPS clouds, and the range of values is wider in PS clouds; this range reaches a maximum of over $2000 \mathrm{mg} \cdot \mathrm{m}^{-3}$ (not shown). In NPS clouds, most of the liquid water content values do not exceed $500 \mathrm{mg} \cdot \mathrm{m}^{-3}$, and the maximum probability of occurrence of approximately $14 \%$ occurs near the $200 \mathrm{mg} \cdot \mathrm{m}^{-3}$ level. The PDFs of the liquid droplet number concentrations associated with both PS and NPS clouds are shown in Figure 4c. The maximum probability in PS clouds is approximately $6.0 \%$ and is located near $80 \mathrm{~cm}^{-3}$. In NPS clouds, the maximum probability of up to $7.3 \%$ is located near $73 \mathrm{~cm}^{-3}$.

Figure $4 \mathrm{~d}$ shows the PDFs of the liquid effective radius in both PS and NPS clouds. The PDF associated with PS clouds displays a much wider range of values than that associated with NPS clouds. The maximum probability is greater and is located at a smaller effective radius in NPS clouds than in PS clouds. The liquid distribution width parameter, which characterizes the varying distribution 
of droplet sizes, is shown in Figure 4e. The values of this parameter exceed 0.27 in both PS and NPS clouds, and the values in PS clouds are generally greater than in NPS clouds. In other words, the droplet size varies more strongly and has a greater spectrum width in PS clouds than in NPS clouds, which favors the formation of precipitation in Sc clouds by coalescence. Considering that the PDFs of radar reflectivity and particle growth are dominated by the condensation process when droplets are smaller than $20 \mu \mathrm{m}$ [41], the primary precipitation type in Sc should be drizzle.

Overall, one striking difference in the PDFs of the microphysical characteristics of PS and NPS clouds is that the ranges of values of the microphysical characteristics are wider in PS clouds than NPS clouds. The wider ranges of values mean that the PS clouds can generate both drizzle and rainfall. Accurate prediction of precipitation from Sc clouds is challenging.

\subsection{Spatial Distributions of the Microphysical Characteristics of Stratocumulus Clouds}

Figure 5 shows the spatial distributions of the average microphysical characteristics of PS and NPS clouds, including the liquid water path, liquid number concentration, and liquid effective radius, over EC. All of the values of the microphysical characteristics of Sc clouds are larger in the precipitating cases than the non-precipitating cases. Because the cloud liquid water path is calculated by integrating the liquid water content through the cloud column, it is related to the cloud thickness: the thicker the cloud, the larger the liquid water path. As we can see from Figure $3 c, f$, NPS cloud thicknesses $(0.5-0.7 \mathrm{~km})$ are uniformly distributed over the ocean and land, and little difference in the liquid water path can be found between ocean and land south of $27^{\circ} \mathrm{N}$ (Figure $5 \mathrm{a}$ ). North of $27^{\circ} \mathrm{N}$, because the westerlies transport warm and wet air from the Bay of Bengal to the lee side of the plateau, the liquid water path over the Sichuan Basin is greater than over its surroundings. The ocean from south of the Korean Peninsula to the northwestern Pacific (not shown) displays the largest liquid water path values because the Kuroshio Current causes the ocean surface temperature to be warmer; thus, the atmospheric stratification is unstable in this area, which favors the vertical transport of water vapor. Conversely, the peak liquid water path value in PS clouds appears over the ocean south of $30^{\circ} \mathrm{N}$, where the frequency of precipitation from Sc clouds is high (Figure $5 \mathrm{~d}$ ). The liquid water path in PS clouds is larger over the ocean than land areas at the same latitude owing to the greater cloud thickness over the ocean.
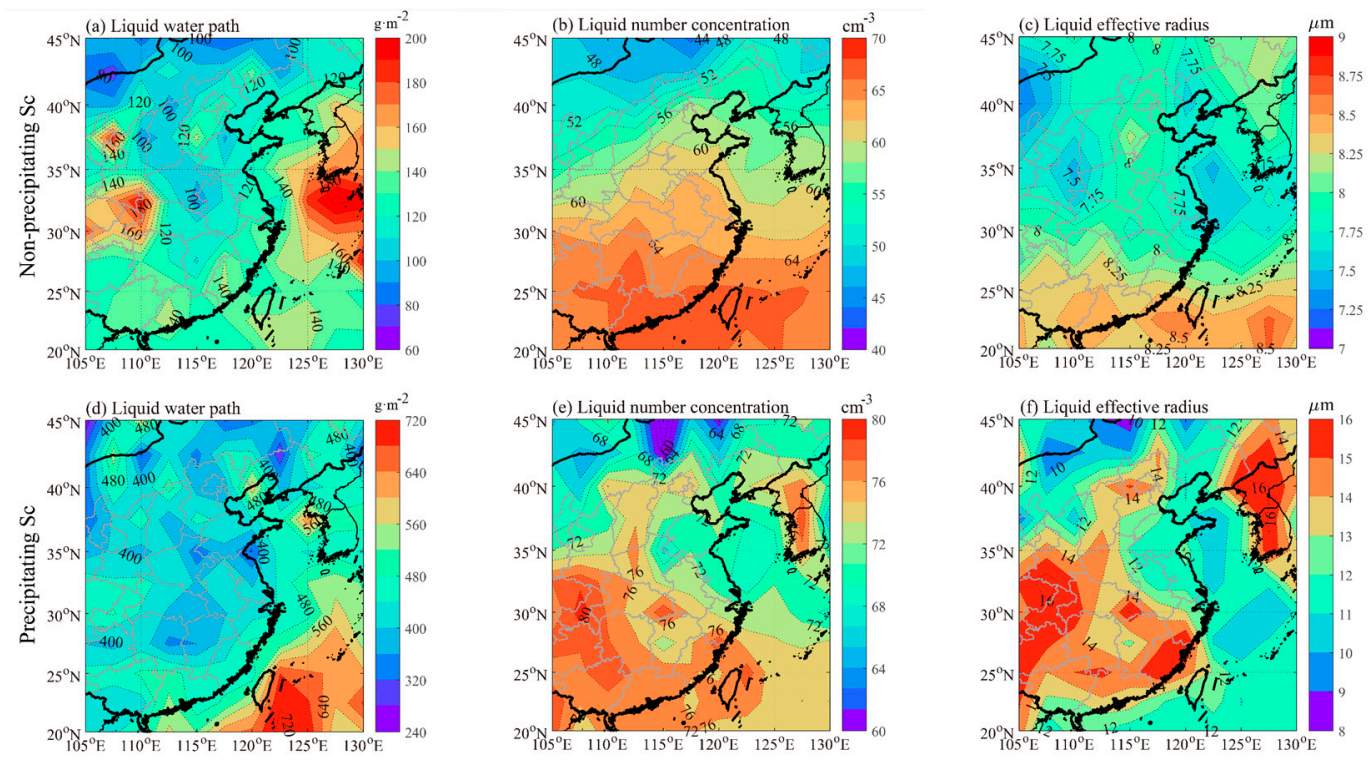

Figure 5. Spatial distributions of the average microphysical characteristics of Sc clouds, including the liquid water path $(\mathbf{a}, \mathbf{d})$, liquid number concentration $(\mathbf{b}, \mathbf{e})$ and liquid effective radius $(\mathbf{c}, \mathbf{f})$ of NPS $(\mathbf{a}-\mathbf{c})$ and PS (d-f) clouds over EC. 
The distributions of the liquid number concentration (Figure $5 b, e$ ) and the liquid effective radius (Figure 5c,f) display similar spatial patterns. For the NPS clouds, both of these microphysical characteristics decrease with latitude. There is little difference in the distributions of microphysical characteristics between the ocean and land areas at the same latitude. For PS clouds, owing to the aerosols produced by anthropogenic activity over land areas acting as cloud condensation nuclei and increasing the cloud drop number concentration, the liquid number concentration over land areas is generally greater than that over the ocean. The land/ocean differences in liquid number concentration and effective radius only occur for PS, not for NPS clouds, perhaps because the stronger updraft over the land increases the height at which significant coalescence begins and also prolongs the lifetime of falling drops promoting larger droplet growth [42]. Peaks in the liquid effective radius of PS clouds appear over the Sichuan Basin, the Southeast Hills, and the Korean Peninsula. These peaks may occur due to the increase in ascending motion driven by high elevations, which result in larger precipitation particles in these areas. Pawlowska and Brenguierhave [43] pointed out that the precipitation rate is strongly dependent on the liquid water path and less-strongly dependent on the number concentration. The distribution of the PS clouds liquid water path (Figure 5d) and the Sc precipitation frequency (Figure 2b) display similar spatial patterns.

\subsection{Vertical Structures of the Microphysical Characteristics of Stratocumulus Clouds}

The internal vertical structure of Sc clouds provides insight into the relevant microscopic properties and microphysical process. Accordingly, we explore the vertical structure of Sc clouds over EC. Figure 6 shows the vertical profiles of mean microphysical properties of PS and NPS clouds. In order to avoid or reduce the impact of terrain, we analyze how the microphysical properties vary with the height above cloud base. In particular, due to the limitation of sample size, heights above $1.8 \mathrm{~km}$ and $2.52 \mathrm{~km}$ are not discussed for NPS and PS clouds, respectively. We also exclude the $0.24 \mathrm{~km}$ thick Sc clouds which contain only one bin.
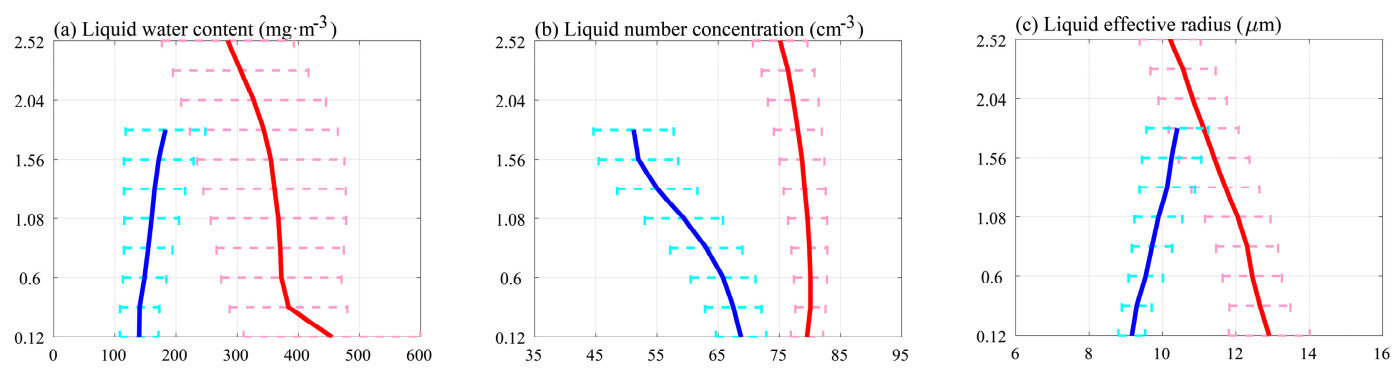

Figure 6. The profiles of mean microphysical properties including liquid water content (a); liquid number concentration (b) and liquid effective radius (c) of PS (red solid curves) and NPS (blue solid curves) clouds. The standard deviations are displayed in short dashed horizontal lines in pink and cyan for PS and NPS clouds, respectively. The vertical coordinate-axis $\mathrm{Y}$ is the height $(\mathrm{km})$ above cloud base.

In NPS clouds, the liquid water content and effective radius increase with height. Contrarily, the liquid number concentration decreases from the cloud base to cloud top. All of the variations of microphysical properties are attributed to the water vapor condensation process. The variation of the liquid water content is consistent with the flight observation from Nicholls and Leighton [44]. The condensation process is initially the primary mechanism for hydrometeor particle growth. In this process, particle size is smaller and particles grow slowly because the condensational growth is inversely proportional to the particle size [42]. Meanwhile, the coalescence process is hindered owing to the low efficiency of collisions and the relative narrow droplet size distributions in NPS clouds [13].

In PS clouds, hydrometeor particles grow by condensation as they rise. When particle size is large enough that the particles are no longer supported by updrafts, the cloud droplets form raindrops and fall. As they fall, the drops increase continuously in size as small hydrometeor particles aggregate, 
resulting in an increase in liquid water content and effective radius from cloud top to cloud base. The liquid number concentration should decrease with decreasing height due to the coalescence processes. However, we speculate that owing to the influence of turbulence, and continuous input cloud water and cloud condensation nuclei, the liquid number concentration changes slightly with height. To this effect, the collision-coalescence process plays an important role in the formation of larger liquid drops.

Sc clouds produce drizzle or rain through collision-coalescence process, but thicker clouds drizzle more readily [13]. Based on the data from CloudSat, the statistical precipitation frequency increases with cloud thickness (not shown). We infer that the vertical structure of Sc clouds in different thickness categories may reflect the clouds' evolution and the precipitation formation process in clouds. In this study, we represent the vertical structure of Sc clouds by the contoured frequency by relative height (height above cloud base) diagrams (CFRHDs) of radar reflectivity and normalize them by the total number of samples at all levels [45] in Figure 7. The solid black lines in figures connect the points at different heights that display the maximum frequencies. The lines (here called the "cloud profiles") represent the basic characteristics of Sc clouds. Considering that the CPR sampling frequency interval is $0.24 \mathrm{~km}$ in the vertical direction, Sc cloud thickness detected by CloudSat should be a multiple of $0.24 \mathrm{~km}$. Thus, we categorize CFRHDs into four groups depending on the clouds thickness $\left(S c_{t k}\right): S c_{t k} \leq 1.20 \mathrm{~km}, S c_{t k}=1.44$ and $1.68 \mathrm{~km}, S c_{t k}=1.92$ and $2.16 \mathrm{~km}, S c_{t k} \geq 2.40$. The cloud layer sample number and cloud precipitation frequency in different thickness categories are marked in the upper-right corner of each figure. In Figure 7, three modes of radar reflectivity are demonstrated: the values of radar reflectivity less than $-15 \mathrm{dBZ}$, in the ranges of -15 to $0 \mathrm{dBZ}$ and larger than $0 \mathrm{dBZ}$, which we interpret as cloud mode, drizzle mode, and rain mode, respectively [40].
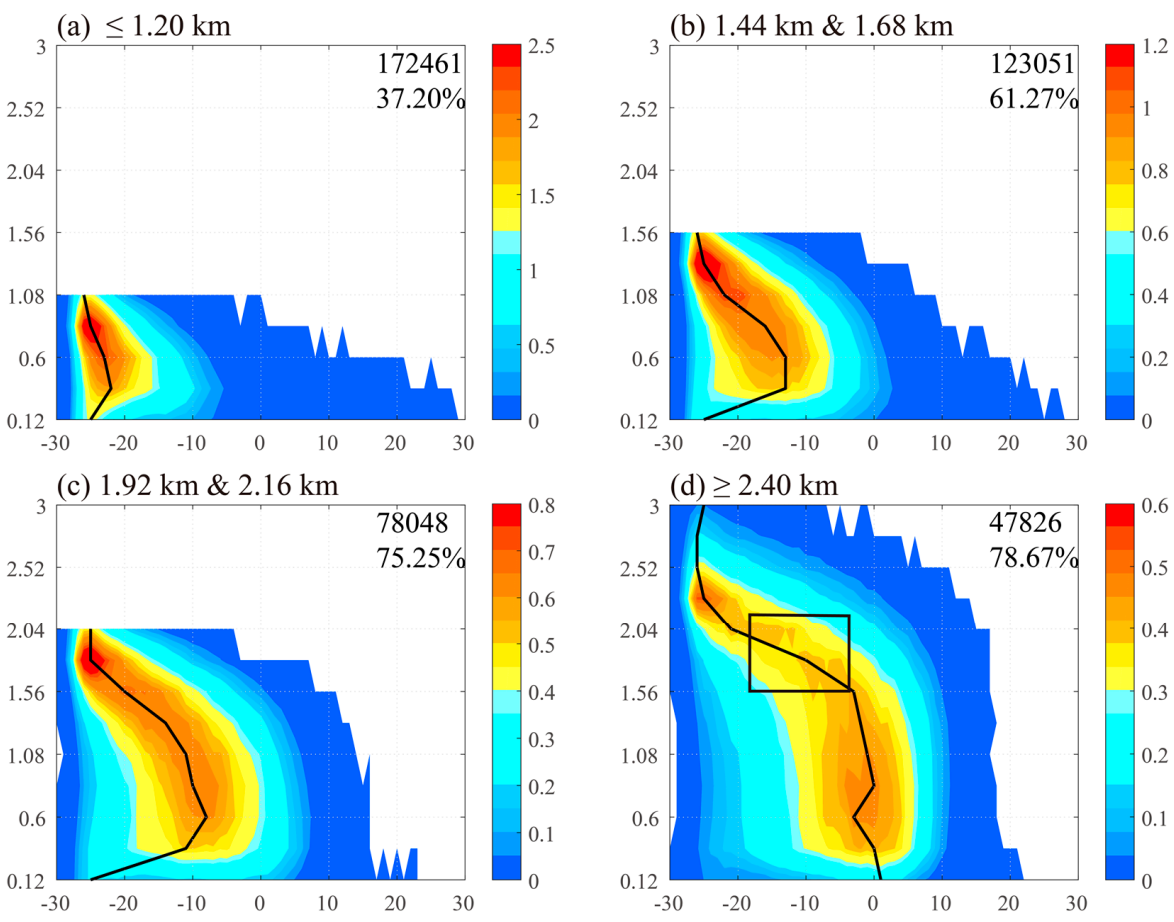

Figure 7. Contoured frequency by relative height (height above cloud base) diagrams (CFRHDs) of radar reflectivity of Sc clouds normalized by the total numbers of samples. The solid black lines connect the points at different heights with the maximum frequencies. According to cloud thickness, CFRHDs are categorized into four groups: $S c_{t k} \leq 1.20 \mathrm{~km}(\mathbf{a}) ; S c_{t k}=1.44$ and $1.68 \mathrm{~km}(\mathbf{b}) ; S c_{t k}=1.92$ and $2.16 \mathrm{~km}$ (c); $S c_{t k} \geq 2.40 \mathrm{~km}$ (d). The Sc clouds layers sample number and cloud precipitation frequency in each thickness categories are marked in the upper-right corner of the figures. The unit of color shading is $\% \cdot \mathrm{dBZ}^{-1}$. The vertical coordinate-axis $\mathrm{Y}$ in figure is the height $(\mathrm{km})$ above cloud base. 
In clouds of the first group (Figure 7a), most of the radar reflectivity values range from -28 to $-15 \mathrm{dBZ}$; the cloud mode is apparent through the entire cloud layer. The cloud profile tends to increase first and then decrease with increasing height. This suggests that the upward particles grow by the condensation process and downward particles grow by collision-coalescence processes. In clouds of the second group, as shown in Figure $7 \mathrm{~b}$, the cloud profile increases with decreasing height above $0.36 \mathrm{~km}$. Some of the values of radar reflectivity are larger than $-15 \mathrm{dBZ}$ at a height of about $0.60 \mathrm{~km}$, which denotes a reference value of drizzle occurrence. This feature appears to indicate that some of the cloud droplets increase by collision-coalescence processes and grow to drizzle at middle and lower layers of clouds. On the other hand, the upward particle growth becomes less pronounced in low layers of clouds. In clouds of the third group (Figure 7c), the character of CFRHDs is found to be similar to that in Figure $7 \mathrm{~b}$. The maximum frequency radar reflectivity increasing downward eventually reaches a value larger than $-10 \mathrm{dBZ}$ at a height of about $0.60 \mathrm{~km}$, likely to represent a continuous transition from cloud droplets to drizzle due to the coalescence process in upper and middle layers of clouds. In clouds of the fourth group, as shown in Figure $4 \mathrm{~d}$, the cloud profile increases rapidly as the height decreases from 2.28 to $1.56 \mathrm{~km}$. At a height below $1.56 \mathrm{~km}$, the cloud profile roughly remains at $0 \mathrm{dBZ}$. The speed of the increase in radar reflectivity slows down in low layers of clouds, implying that the collection process tends to be inefficient [40]. The contoured frequencies appear bimodal: one peak is near the cloud top, the other peak is near the cloud base, which we interpret as cloud mode and drizzle (or rain) mode, respectively. At a height between 1.56 and $2.04 \mathrm{~km}$, the drizzle mode becomes less pronounced (highlighted as a black rectangle in Figure 4d). Takahashi et al [42] pointed out that the reflectivity gap in drizzle mode results from stronger updrafts, especially over the land. The stronger updrafts can lift relatively smaller particles near the cloud top and promote particle growth; only the cloud droplets growing to drizzle or even rain drops can fall against the updrafts. In particular, with the increase of cloud thickness, thicker Sc clouds provide a wider growing space for hydrometeor particles. Particles can grow for a long period of time and grow to larger sizes, resulting in increased precipitation frequency.

\section{Summary}

The macro- and microphysical characteristics of PS and NPS clouds over EC from June 2006 to December 2010 are quantitatively analyzed in this study using CloudSat data. We observe significant differences in the macro- and microphysical characteristics, as well as microphysical processes, between PS and NPS clouds.

The statistical properties of the macroscopic characteristics show that Sc clouds are much more likely to occur alone over EC, considering the year-to-year or seasonal variability, and the associated precipitation frequency is approximately $25 \%$. However, when Sc clouds occur with other cloud types, altostratus (As), altocumulus (Ac), and high clouds are the most common. The frequency of precipitation from Sc clouds is greater south of $35^{\circ} \mathrm{N}$ than over the northern part of the study region. The precipitation frequency over the ocean is also greater than that over land areas at the same latitude. The cloud tops of PS clouds are higher, the cloud bases are lower, and the cloud thicknesses are greater than those of NPS clouds.

We also analyze the spatial distributions of the microphysical characteristics of Sc clouds over EC, including the liquid water path, liquid number concentration, and liquid effective radius. The peak of the liquid water path is located over the ocean in both PS and NPS clouds, but this peak is located farther north in NPS clouds. The liquid number concentration and liquid effective radius decrease as latitude increases in NPS clouds. In PS clouds, the magnitudes of the values of microphysical characteristics are greater over land areas than over the ocean. The spatial distributions of microphysical characteristics are strongly influenced by the generating circulation and terrain.

The variations in microphysical properties with height reflect microphysical processes that operate in clouds. The cloud profiles of mean microphysical properties differ markedly between PS and NPS clouds. In NPS clouds, the hydrometeor particles grow by the condensation process as they rise, 
resulting in the liquid water content and effective radius increase from cloud base to cloud top. In PS clouds, when particles grow by condensation to large sizes, they fall against the updrafts and grow due to the collision-coalescence process. In this process, the liquid water content and effective radius increase with decreasing height.

The CFRHDs of radar reflectivity reflect the statistical distributions of clouds properties. With the purpose to explore the Sc cloud evolution and precipitation formation process, Sc clouds are categorized into four groups depending on their thickness. The Sc precipitation frequency increases with cloud thickness. Within relatively thinner clouds, the upward particle growth by the condensation process and downward particle growth by collision-coalescence processes occur in the lower and upper layers of clouds, respectively. In 1.44 and $1.68 \mathrm{~km}$ thick Sc clouds, the falling particles grow due to the collection of cloud droplets through the cloud layer. In Sc clouds thicker than $1.68 \mathrm{~km}$, the continuous transition from cloud droplets to drizzle even to raindrops by the collision-coalescence process occurs mostly in the upper layers of clouds. The particles grow slowly in the lower part of cloud layers. In particular, the drizzle mode in Sc clouds thicker than $2.40 \mathrm{~km}$ becomes less pronounced in upper layers of clouds, which may result from the stronger updrafts that prolong the smaller particles' lifetime and promote particle growth in the vicinity of the cloud top.

Although quantitative and theoretical in nature, this study may contribute to a better and more comprehensive understanding of the mechanisms by which precipitation is generated in different thickness categories of Sc clouds. This work also provides a workable reference for validating and improving the parameterization schemes used in existing regional climate models. For example, this study can provide a verification for the model-simulated liquid water content and can provide more realistic liquid number concentrations for different precipitation species in one-moment microphysics schemes. In the future, we plan to integrate the standard CloudSat data product 2C-PRECIP-COLUMN, which provides relatively accurate data on precipitation rates over the ocean, to further explore the differences in microphysical characteristics between PS and NPS clouds.

Author Contributions: S.L. and Y.L. designed the research. S.L., G.S. and Z.L. carried out experiments and prepared the all figures. S.L and Y.L. drafted and revised manuscript. All the authors discussed the results and commented on the manuscript.

Funding: This research was funded by the National Natural Science Foundation of China (grant 41475069) and the China R\&D Special Fund for Public Welfare Industry (meteorology: GYHY 201306068).

Acknowledgments: The data used in this study were got from the CloudSat website (http:/ / www.cloudsat.cira. colostate.edu). We are also grateful to three anonymous reviewers for their valuable comments.

Conflicts of Interest: The authors declare no conflict of interest.

\section{References}

1. Hahn, C.J.; Warren, S.G. A Gridded Climatology of Clouds over Land (1971-96) and Ocean (1954-97) from Surface Observations Worldwide; Numeric Data Product NDP-026E, Carbon Dioxide Information Analysis Center; Oak Ridge National Laboratory: Oak Ridge, TN, USA, 2007. [CrossRef]

2. Klein, S.A.; Hartmann, D.L. The seasonal cycle of low stratiform clouds. J. Clim. 1993, 6, 1587-1606. [CrossRef]

3. Yu, R.C.; Yu, Y.Q.; Zhang, M.H. Comparing cloud radiative properties between the Eastern China and the Indian monsoon region. Adv. Atmos. Sci. 2001, 18, 1090-1102. [CrossRef]

4. Li, Y.Y.; Gu, H. Relationship between middle stratiform clouds and large scale circulation over eastern China. Geophys. Res. Lett. 2006, 330, 881. [CrossRef]

5. Ghate, V.P.; Albrecht, B.A.; Kollias, P. Vertical velocity structure of nonprecipitating continental boundary layer stratocumulus clouds. J. Geophys. Res. Atmos. 2010, 115. [CrossRef]

6. Rapp, A.D.; Lebsock, M.; Ecuyer, T.L. Low cloud precipitation climatology in the southeastern Pacific marine stratocumulus region using CloudSat. Environ. Res. Lett. 2013, 8, 014027. [CrossRef] 
7. Stevens, B.; Beljaars, A.; Bordoni, S.; Holloway, C.; Köhler, M.; Krueger, S.; Savic-Jovcic, V.; Zhang, Y. On the structure of the lower troposphere in the summertime stratocumulus regime of the northeast Pacific. Mon. Weather Rev. 2007, 135, 985-1005. [CrossRef]

8. Wood, R.; Mechoso, C.R.; Bretherton, C.S.; Weller, R.A.; Huebert, B.; Straneo, F.; Albrecht, B.A.; Coe, H.; Allen, G.; Vaughan, G.; et al. The VAMOS ocean-cloud-atmosphere-land study regional experiment (VOCALS-REx): Goals, platforms, and field operations. Atmos. Chem. Phys. 2011, 11, 627-654. [CrossRef]

9. Leon, D.C.; Wang, Z.; Liu, D. Climatology of drizzle in marine boundary layer clouds based on 1 year of data from CloudSat and Cloud-Aerosol Lidar and Infrared Pathfinder Satellite Observations (CALIPSO). J. Geophys. Res. Atmos. 2008, 113. [CrossRef]

10. Nakajima, T.Y.; Suzuki, K.; Stephens, G.L. Droplet growth in warm water clouds observed by the A-Train. Part II: A multisensor view. J. Atmos. Sci. 2010, 67, 1897-1907. [CrossRef]

11. Suzuki, K.; Stephens, G.; Bodassalcedo, A.; Wang, M.; Golaz, J.E.; Yokohata, T.; Koshiro, T. Evaluation of the warm rain formation process in global models with satellite observations. J. Atmos. Sci. 2015, 72, 3996-4014. [CrossRef]

12. Magaritzronen, L.; Pinsky, M.; Khain, A. Drizzle formation in stratocumulus clouds: Effects of turbulent mixing. Atmos. Chem. Phys. 2015, 15, 24131-24177. [CrossRef]

13. Wood, R. Stratocumulus Clouds. Am. Meteorol. Soc. 2012, 140, 2373-2423. [CrossRef]

14. Wang, M.Y.; Gu, J.X.; Yang, R.Z.; Zeng, L.; Wang, S. Comparison of cloud type and frequency over China from surface, FY-2E, and CloudSat observations. Proc. SPIE 2014, 9259, 13-27. [CrossRef]

15. Li, Y.Y.; Yu, R.C.; Xu, Y.P.; Zhang, X.H. Spatial distribution and seasonal variation of cloud over China based on ISCCP data and surface observations. J. Meteorol. Soc. Jpn. 2004, 82, 761-773. [CrossRef]

16. Zhang, Y.; Chen, H.M.; Yu, R.C. Simulations of stratus clouds over Eastern China in CAM5: Sensitivity to horizontal resolution. J. Clim. 2014, 27, 7033-7052. [CrossRef]

17. Zhang, Y.; Li, J. Shortwave cloud radiative forcing on major stratus cloud regions in AMIP-type simulations of CMIP3 and CMIP5 models. Adv. Atmos. Sci. 2013, 30, 884-907. [CrossRef]

18. Bony, S.; Dufresne, J.L. Marine boundary layer clouds at the heart of tropical cloud feedback uncertainties in climate models. Geophys. Res. Lett. 2005, 32, L20806. [CrossRef]

19. Lin, Y.; Colle, B.A. A new bulk microphysical scheme that includes riming intensity and temperature-dependent ice characteristics. Mon. Weather Rev. 2009, 139, 1013-1035. [CrossRef]

20. Morrison, H.; Thompson, G.; Tatarskii, V. Impact of cloud microphysics on the development of trailing stratiform precipitation in a simulated squall line: Comparison of one- and two-moment schemes. Mon. Weather Rev. 2009, 137, 991-1007. [CrossRef]

21. Rajeevan, M.; Rohini, P.; Kumar, K.N.; Srinivasan, J.; Unnikrishnan, C.K. A study of vertical cloud structure of the Indian summer monsoon using CloudSat data. Clim. Dyn. 2013, 40, 637-650. [CrossRef]

22. Jiang, X.; Waliser, D.E.; Li, J.L.; Srinivasan, J.; Unnikrishnan, C.K. Vertical cloud structures of the boreal summer intraseasonal variability based on CloudSat observations and ERA-interim reanalysis. Clim. Dyn. 2011, 36, 2219-2232. [CrossRef]

23. Zhang, Y.; Chen, H.M.; Yu, R.C. Vertical structures and physical properties of the cold-season stratus clouds downstream of the Tibetan Plateau: Differences between daytime and nighttime. J. Clim. 2014, 27, 6857-6876. [CrossRef]

24. Kiran, V.R.; Rajeevan, M.; Gadhavi, H.S.; Rao, V.B.; Jayaraman, A. Role of vertical structure of cloud microphysical properties on cloud radiative forcing over the Asian monsoon region. Clim. Dyn. 2015, 45, 3331-3345. [CrossRef]

25. Sassen, K.; Wang, Z. Level 2 Cloud scenario classification product process description and interface control document. Version 2007, 5, 50 .

26. Stephens, G.L.; Vane, D.G.; Tanelli, S.; Im, E.; Durden, S.; Rokey, M.; Reinke, D.; Partain, P.; Mace, G.G.; Austin, R. CloudSat mission: Performance and early science after the first year of operation. J. Geophys. Res. 2009, 113, 2036-2044. [CrossRef]

27. Yuan, J.; Houze, R.A.J.; Heymsfield, A.J. Vertical structures of anvil clouds of tropical mesoscale convective systems observed by CloudSat. J. Atmos. Sci. 2011, 68, 1653-1674. [CrossRef]

28. Li, Y.Y.; Zhang, M.H. Cumulus over the Tibetan Plateau in the summer based on CloudSat-CALIPSO data. J. Clim. 2016, 29, 1219-1230. [CrossRef] 
29. Sassen, K.; Wang, Z.E. Classifying clouds around the globe with the CloudSat radar: 1-year of results. Geophys. Res. Lett. 2008, 35, L04805. [CrossRef]

30. Hudak, D.; Rodriguez, P.; Donaldson, N. Validation of the CloudSat precipitation occurrence algorithm using the Canadian C band radar network. J. Geophys. Res. 2008, 113, D00A07. [CrossRef]

31. Mace, G. Level 2 GEOPROF Product Process Description and Interface Control Document; Nasa Jet Propulsion Laboratory: Pasadena, CA, USA, 2001.

32. Wood, N. Level 2B Radar-Visible Optical Depth Cloud Water Content (2B-CWC-RVOD) Process Description Document. Version 2008, 5, 1-26.

33. Barker, H.W.; Korolev, A.V.; Hudak, D.R.; Strapp, J.W.; Strawbridge, K.B.; Wolde, M. A comparison between CloudSat and aircraft data for a multilayer, mixed phase cloud system during the Canadian CloudSat-CALIPSO Validation Project. J. Geophys. Res. Atmos. 2008, 113, D00A16. [CrossRef]

34. Lee, S.; Kahn, B.H.; Teixeira, J. Characterization of cloud liquid water content distributions from CloudSat. J. Geophys. Res. 2010, 115, D20203. [CrossRef]

35. Christensen, M.W.; Stephens, G.L.; Lebsock, M.D. Exposing biases in retrieved low-cloud properties from cloudsat: A guide for evaluating observations and climate data. J. Geophys. Res. Atmos. 2013, 118, 120-131. [CrossRef]

36. Quante, M. The role of clouds in the climate system. J. Phys. IV 2004, 121, 1-26. [CrossRef]

37. Warren, S.G.; Hahn, C.J.; London, J. Simultaneous occurrence of different cloud types. J. Appl. Meteorol. 1985, 24, 658-668. [CrossRef]

38. Rossow, W.B.; Walker, A.W.; Garder, L.C. Comparison of ISCCP and other cloud amounts. J. Clim. 1993, 6, 2394-2418. [CrossRef]

39. Biggerstaff, M.I.; Listemaa, S.A. An improved scheme for convective/stratiform echo classification using radar reflectivity. J. Appl. Meteorol. 2000, 39, 2129-2150. [CrossRef]

40. Suzuki, K.; Nakajima, T.Y.; Stephens, G.L. Particle growth and drop collection efficiency of warm clouds as inferred from joint CloudSat and MODIS observations. J. Atmos. Sci. 2010, 67, 3019-3032. [CrossRef]

41. Wallace, M.J.; Hobbs, P.V. Atmospheric Science: An Introductory Survey; Elsevier: New York City, NY, USA, 2006; p. 488.

42. Takahashi, H.; Suzuki, K.; Stephens, G. Land-ocean differences in the warm-rain formation process in satellite and ground-based observations and model simulations. Q. J. R. Meteorol. Soc. 2017, 143, 1804-1815. [CrossRef]

43. Pawlowska, H.; Brenguier, J. An observational study of drizzle formation in stratocumulus clouds for general circulation model (GCM) parameterizations. J. Geophys. Res. Atmos. 2003, 108, 8630. [CrossRef]

44. Nicholls, S.; Leighton, J. An observational study of the structure of stratiform cloud sheets: Part I. Structure. Q. J. R. Meteorol. Soc. 1986, 112, 431-460. [CrossRef]

45. Yuter, S.E.; Houze, R.A. Three-dimensional kinematic and microphysical evolution of Florida cumulonimbus. Part II: Frequency distributions of vertical velocity, reflectivity, and differential reflectivity. Mon. Weather Rev. 1995, 123, 1921-1940. [CrossRef]

(C) 2018 by the authors. Licensee MDPI, Basel, Switzerland. This article is an open access article distributed under the terms and conditions of the Creative Commons Attribution (CC BY) license (http://creativecommons.org/licenses/by/4.0/). 